American Journal of Pharmaceutical Education 2020; 84 (10) Article 7314.

\title{
RESEARCH
}

\section{Characterization of Veterinary Pharmacy and Pharmacology Literature and its Availability to Pharmacy Education}

\author{
Kristine M. Alpi, PhD, MLS, MPH, ${ }^{a}$ Emma Stafford, PharmD, ${ }^{b}$ Emily M. Swift, PharmD, \\ Sarah Danehower, MB, ${ }^{\mathrm{d}}$ Heather I. Paxson, MA, ${ }^{\mathrm{e}}$ Gigi Davidson, BSPharm ${ }^{\mathrm{f}, \mathrm{g}}$ \\ ${ }^{a}$ Oregon Health \& Science University, OHSU Library, Portland, Oregon \\ ${ }^{\mathrm{b}}$ University of Missouri-Kansas City School of Pharmacy, Kansas City, Missouri \\ ${ }^{\mathrm{c}}$ North Carolina State University Veterinary Hospital Pharmacy, Raleigh, North Carolina \\ ${ }^{\mathrm{d}}$ Drexel University, School of Medicine, Philadelphia, Pennsylvania \\ ${ }^{\mathrm{e}}$ North Carolina State University, Raleigh, North Carolina \\ ${ }^{\mathrm{f}}$ American College of Veterinary Pharmacists, Memphis, Tennessee \\ ${ }^{g}$ VetPharm Consulting, LLC, Pittsboro, North Carolina \\ Submitted August 6, 2018; accepted March 26, 2020; published October 2020.
}

Objective. To characterize the veterinary pharmacy and pharmacology literature cited by veterinary drug monographs and journal articles and describe the database indexing and availability of this literature in libraries serving pharmacy schools.

Methods. Citations in American Academy of Veterinary Pharmacology and Therapeutics monographs, Journal of Veterinary Pharmacology and Therapeutics (JVPT) articles, and Plumb's Veterinary Drug Handbook, Eighth Edition (Plumb's) were analyzed for publication type and age. Three zones of cited journals were determined by Bradford's Law of Scattering based on citation counts.

Results. Monographs most often cited journal articles (1886 [64.7\%]), unpublished "grey" literature (632 [21.7\%]), and books (379 [13.0\%]), but only a few cited proceedings (16 [0.5\%]). In JVPT, articles predominated (9625 [91.9\%]). Articles comprised 54.8\% (1,959) of Plumb's citations; proceedings, $27.0 \%$; books, $15.7 \%$; and grey literature, $2.5 \%$. The age of cited items varied, with $17.1 \%$ of monograph citations less than five years old, compared to $26.3 \%$ of cited items in JVPT and $40.5 \%$ of cited items in Plumb's being less than five years old. Zone 1 consisted of three veterinary journals for monographs, four veterinary journals for Plumb's, and 16 veterinary and human journals for JVPT. Indexing coverage was above 92\% in Web of Science, Scopus, and PubMed for zone 1 and 2 journals. Libraries serving both pharmacy and veterinary education programs subscribe to $95 \%$ of zone 1 journals, while libraries serving pharmacy education at institutions without a veterinary program subscribe to an average of $59 \%$ of zone 1 journals.

Conclusion. Veterinary pharmacy and pharmacology literature relies on journals from human and veterinary practice, veterinary proceedings, and, less often, books and drug manufacturer information. Libraries supporting pharmacy programs could contribute to the education of future pharmacists who will be filling veterinary prescriptions by increasing access to this literature.

Keywords: veterinary pharmacy, drug monographs, abstracts and indexing, bibliometrics, pharmacy libraries

\section{INTRODUCTION}

Veterinary pharmacists are pharmacists with specialized knowledge and training in providing pharmaceutical care and products for non-human species, while veterinary pharmacologists are veterinarians credentialed

Corresponding Author: Kristine M. Alpi, Oregon Health \& Science University, 3181 SW Sam Jackson Park Rd. MC LIB, Portland, OR 97239-3098. Tel: 503-494-4055. Email:

alpi@ohsu.edu. in veterinary pharmacology. These differences in education give rise to variations in the use and evaluation of information resources by these professionals. Like all licensed pharmacists in the United States, veterinary pharmacists train at pharmacy schools accredited by the Accreditation Council for Pharmacy Education and study human-centered coursework in medicinal chemistry, pharmacology, and pharmacotherapeutics. Because veterinary medicine encompasses all species, and there is often little data describing the medication of interest for a 


\section{American Journal of Pharmaceutical Education 2020; 84 (10) Article 7314.}

specific species, knowing how to access evidence is vital. While pharmacists are the only health care provider that society expects to provide care for all species, there is a deficit in veterinary pharmacotherapy education at pharmacy schools. ${ }^{1}$ Postgraduate options for specializing in veterinary pharmacy include postgraduate year one residencies offered at North Carolina State, Purdue, the University of Wisconsin, University of California at Davis, and Texas A\&M College of Veterinary Medicine. Completing a residency program prepares the pharmacist to conduct clinical evaluations of all species and provides training in species-specific anatomy, physiology, toxicology, veterinary-only medications, and regulatory concerns specific to veterinary medicine. Because there are limited residency positions in veterinary pharmacy, specializing in this area remains a rare career focus for pharmacists.

The majority of members of the American College of Veterinary Pharmacists provide a combination of human and veterinary pharmacy services and focus primarily on compounding. However, the most likely career for a veterinary pharmacy specialist is in a teaching hospital associated with a college of veterinary medicine. Fiftyfive percent of the pharmacist members of the Society of Veterinary Hospital Pharmacists practice exclusively in veterinary teaching hospitals. Additionally, veterinary pharmacists can use their unique knowledge in research, industry, and regulatory settings as medications developed for use in humans are routinely tested in animal patients prior to use in human clinical trials. This knowledge can also be applied in community pharmacy as shown by a survey of more than 13,000 licensed pharmacists in North Carolina in which $77 \%$ of respondents revealed that they routinely filled prescriptions for animal patients. ${ }^{2}$ However, $61 \%$ of the respondents felt less than confident in their ability to verify the appropriateness of veterinary prescriptions. A similar survey of Oregon pharmacists found that $77 \%$ of respondents routinely filled prescriptions for veterinary patients although they had had little or no training in veterinary pharmacotherapy. ${ }^{3}$

Many states require veterinarians to provide a written prescription upon request to animal owners who may prefer to have the medication provided by a pharmacy rather than their veterinarian. A 2015 Food and Drug Administration guidance document estimated that 75,000 pharmacies fill 6,350,000 compounded prescriptions for animal patients annually. ${ }^{4}$ This volume of veterinary prescriptions being dispensed annually highlights the importance of prospective education for pharmacy students during their coursework, as well as after graduation, to ensure they know how to find drug information to guide their clinical decision making. This training would also ensure exposure to the literature of veterinary pharmacy and pharmacology for those planning to, or currently practicing, in community and compounding pharmacies. A 2014 resolution by the National Association of Boards of Pharmacy (NABP) stated that pharmacists dispensing veterinary medications should possess competence in this area and have access to relevant resources necessary to provide excellent patient care for veterinary patients. ${ }^{5}$ Nevertheless, the ability to identify and critically evaluate evidence-based veterinary information continues to be challenging for most pharmacists. The NABP resolution also encourages educational collaboration between colleges of veterinary medicine and pharmacy to ensure that pharmacists are competent to fill veterinary prescriptions. A 2015 survey by Arnish and colleagues found that only $22 \%$ of responding pharmacy schools offered a veterinary pharmacy elective, and that only $4 \%$ of graduates from those schools had completed this elective. ${ }^{1}$

This investigation was based on our experience that veterinary pharmacy literature involves diverse information sources that are not well-indexed or held by human health sciences libraries. Characterizing veterinary pharmacy and pharmacology literature will allow pharmacists and librarians to identify the journals and other sources most commonly cited in veterinary drug information literature. This may help fill the educational void for pharmacists seeking information regarding treatment of non-human species. The purpose of this study was to characterize the literature relevant to veterinary pharmacy practice by identifying the variety of publications cited by authors of veterinary drug content and describe the discoverability and availability of the cited journals in libraries serving pharmacy students.

\section{METHODS}

The Medical Library Association's Nursing and Allied Health Resources Section mapping protocol $^{7}$ applied to hospital pharmacy literature ${ }^{8}$ was expanded on to develop this investigation. However, no veterinary pharmacy professional organization published a peerreviewed journal that could be used as the basis of this analysis; therefore, we expanded our analysis to include veterinary pharmacology and chose the 2016-2018 articles from the Journal of Veterinary Pharmacology and Therapeutics (JVPT), which is the peer-reviewed journal published by the American Academy of Veterinary Pharmacology and Therapeutics (AAVPT). This journal is the only current pharmacology and therapeutics title on the core list of veterinary serials. ${ }^{6}$ Additional resources selected for mapping included nearly 800 drug monographs from the Plumb's Veterinary Drug Handbook, Eighth Edition (Plumb's), a pharmacist-produced resource 


\section{American Journal of Pharmaceutical Education 2020; 84 (10) Article 7314.}

used frequently by veterinary pharmacists. Resources also included 43 open-access veterinary drug information monographs published by the AAVPT that had been widely consulted by veterinarians and veterinary pharmacists. The AAVPT monographs were originally published between 1993 and 2008 by members of the Veterinary Drugs Expert Committee of the United States Pharmacopeial Convention, with the most recent updates made by AAVPT from 2003-2016.

For each monograph from AAVPT and Plumb's, the following elements were extracted and entered in a spreadsheet: drug name, broad category, date monograph developed, date of last revision, number of cited references, and all individual cited references. For each cited reference, the year of publication and the journal, book, or conference proceeding title were extracted. The age of each citation was calculated by subtracting the year of the cited item from the year of the last revision of the published monograph or the JVPT article publication year. Citations without a date were categorized as "unknown." Each citation was classified by publication type as journal, book, conference proceeding, or other. "Other" consisted primarily of manufacturer-produced information and legal information, as well as panel comments, clinical laboratory standards, dissertations/theses, and personal communications. Most of these items would be considered grey literature as they are not indexed in traditional databases.

Two veterinary pharmacy residents independently categorized journals as being primarily human, veterinary, or multidisciplinary. For example, New England Journal of Medicine was categorized as human, while Journal of the American Veterinary Medical Association was categorized as veterinary. If journal titles referenced human and veterinary medicine equally or dealt mainly with basic science (eg, chemistry, biochemistry), they were categorized as multidisciplinary. For titles on which the residents did not agree $(27.9 \%)$, two library staff members decided after consulting PubMed for the percentage of human and non-human articles in the journal and seeing whether the journal had a designation in a previous One Health study that used a similar categorization. ${ }^{9}$

To identify a core set of journals for veterinary pharmacy and pharmacology, methodology was applied from mapping the literature studies ${ }^{7}$ based on Bradford's Law of Scattering, which states how "a relatively small core of journals can be expected to account for a disproportionate amount of the literature." ${ }^{\prime 10}$ Cited reference journal titles were ranked by citation counts, and as Bradford's Law suggests that the majority of cited references will come from a relatively small number of "core" journals, and the remaining references will be more widely dispersed among a larger number of peripheral journals, three zones were delineated, with those journals providing the top one-third of the citations comprising zone 1 and the remaining thirds comprising zones 2 and 3, respectively.

The databases chosen were PubMed, ${ }^{11}$ EMBASE, ${ }^{12}$ International Pharmaceutical Abstracts, ${ }^{13} \mathrm{CAB} \mathrm{Ab}$ stracts, ${ }^{14}$ Web of Science, ${ }^{15}$ and Scopus. ${ }^{16}$ Indexing analysis focused on the 303 unique zone 1 and 2 journal titles remaining after combining name changes and absorptions of titles. Database coverage was identified as "yes" or "no" based on the journal's presence in the list of journals currently indexed rather than using the indexing coverage method reported in other mapping studies done at a time when some journals were selectively indexed. Journals not on the currently indexed title lists in 2016 were searched to see whether they had been indexed at the time the article was published. Data for journals added through the JVPT analysis for 2016-2018 were checked in October 2019. Although EMBASE.com includes MEDLINE, only titles with EMBASE indexing were included for the EMBASE coverage. Indexing coverage across databases was compared using the chi-square test on Open Epi (http://www.openepi.com/) and $\mathrm{z}$ tests comparing two proportions on EpiTools Epidemiological Calculators. ${ }^{17}$ Conference indexing was not assessed as only CAB Abstracts covers conference proceedings in its core product.

A list of veterinary colleges $(\mathrm{N}=30)$ was generated from the Association of American Veterinary Medical Colleges website ${ }^{18}$ and a list of institutional member schools of pharmacy including branch campus locations $(\mathrm{N}=152)$ was generated from the American Association of Colleges of Pharmacy ${ }^{19}$ to assess library holdings of core journals. Multiple pharmacy programs that appeared to be branches of the same institution served by a single library or sharing journal collections across locations were represented only once in the data set. For comparative analysis, the libraries were divided into three categories: both (serving both pharmacy and veterinary medicine), veterinary medicine (serving no pharmacy program), and pharmacy (serving no veterinary medical program). Within the pharmacy category, there was a subgroup of schools that reported offering a veterinary pharmacy elective course in $2015 .^{1}$

Each journal in the zone 1 and zone 2 lists from the AAVPT monographs and Plumb's as well as the zone 1 list from JVPT $(\mathrm{N}=27)$ was searched in the WorldCat shared catalog (worldcat.org) to determine whether it was held at each of the libraries. For the 16 programs whose libraries did not participate in WorldCat, the library 
website was visited to search the library's online catalog for access to recent content of the journal. Embargoed access within one year of current was considered to constitute access. Ten libraries lacked a publicly available online catalog or journal list; those libraries were excluded from the analysis as details of their subscriptions could not be confirmed. The final list included 148 libraries. The same statistical methods used for indexing comparisons were used to identify between group differences in the holding percentages. Means between groups were compared using two-tailed two-sample $t$ tests for summary data with the significance level set at 0.05 .

\section{RESULTS}

The types of publications cited and their citation age are shown in Table 1. Across all publications cited in the monographs, only $17.1 \%$ were published within five years of the last revision of the monograph in which they were cited. JVPT articles referenced publications within the previous five years at a significantly higher rate $(26.3 \%)$ than the monographs $(\mathrm{Z}=10.2, p<.001)$. The proportion of citations in Plumb's (a handbook that guides prescribing) that had been published in the past five years $(40.5 \%)$ was significantly higher than the rate in JVPT $(\mathrm{Z}=16.1, p<.001)$.

Journals $(n=1886,64.7 \%)$ were the most heavily cited publication type by the monographs, but they also relied on books $(n=379,13.0 \%)$ and other/grey literature $(\mathrm{n}=632,21.7 \%)$, such as drug manufacturer information, and conference proceedings $(\mathrm{n}=16,0.5 \%)$. In $J V P T$, journal articles predominated $(n=9625,91.9 \%)$ over grey literature $(n=412,3.9 \%)$, books $(n=380,3.6 \%)$, and proceedings $(n=62,0.6 \%)$. The greater reliance on journals for JVPT (91.9\%) compared with journal citations in the AAVPT monographs $(64.7 \%)$ was significant $(\mathrm{Z}=37.2, p<.001)$. Publication types were more varied in Plumb's citations, with journals comprising 54.8\% $(n=1,959)$; conference proceedings, $27.0 \%(n=964)$; books, $15.7 \%(n=562)$; and grey literature, $2.5 \%(n=89)$.

The number of journal titles in each source divided by zones (Table 2) shows that the AAVPT monographs relied heavily on three veterinary journal titles and that these zone 1 titles generated a third of all citations. Zone 2 for the monographs consisted of citations from 12 journals, also mostly veterinary journal titles $(9,75.0 \%)$ with few multidisciplinary $(2,16.7 \%)$ or human $(1,8.3 \%)$ journal titles. The zone 1 size and composition in Plumb's is similar to the AAVPT, with four veterinary titles. Zone 1 for $J V P T$ is more diverse than the monograph zones, with 16 journal titles. Of these, $11(68.8 \%)$ were veterinary journals, three (18.8.\%) were multidisciplinary journals, and two (12.5\%) were human journals. See

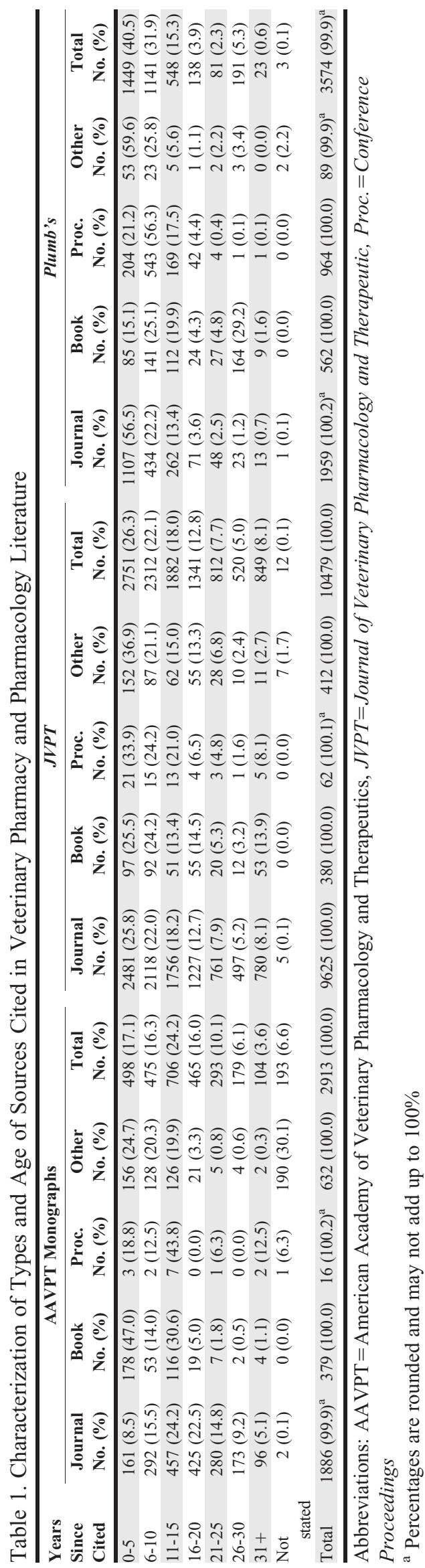


American Journal of Pharmaceutical Education 2020; 84 (10) Article 7314.

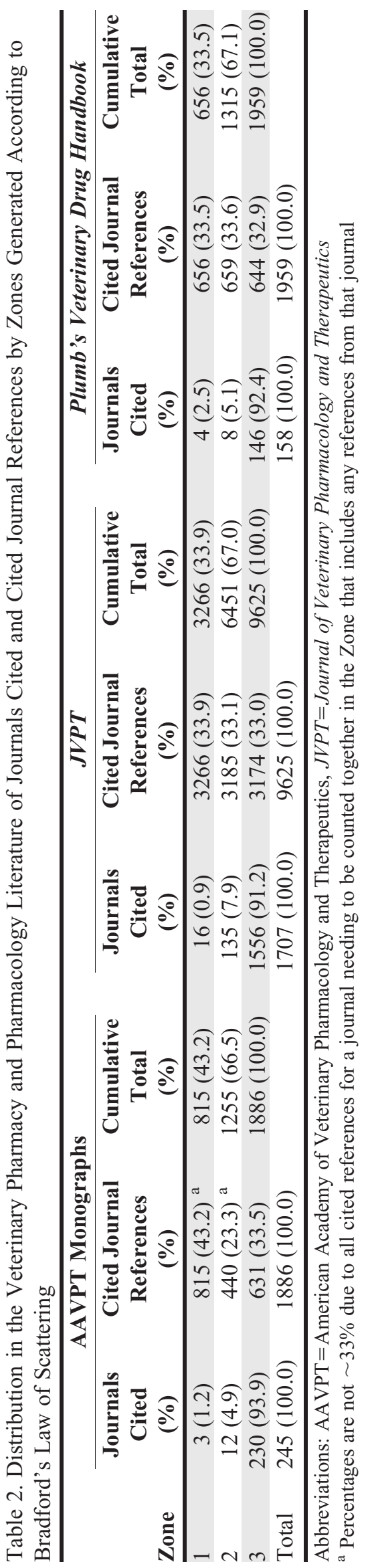

Appendix 1 for the categorization for the 27 journals in zone 1 from $J V P T$ and zones 1 and 2 from the monographs and Plumb's.

The top 10 cited journals vary across sources (Table 3 ), with only four titles making up the top 10 for all sources: American Journal of Veterinary Research, JVPT, Journal of the American Veterinary Medical Association, and Journal of Veterinary Internal Medicine. Four more titles were highly cited in two of the three sources.

As shown in Figure 1, Web of Science, Scopus, and PubMed each cover over $92 \%$ of these titles, followed closely by $\mathrm{CAB}$ Abstracts and EMBASE. As International Pharmaceutical Abstracts (IPA) coverage (18.5\%) was very different than the others, it was not included in the statistical comparison. The chi-square test comparing all other databases was significant $\left(\chi^{2}[4, \mathrm{~N}=5]=42.2\right.$, $p<.001)$. The difference between Web of Science and Scopus indexing was not significant, nor was the difference between Scopus and PubMed. The 4\% difference between Web of Science and PubMed was significant $(Z=2.1$, $p<.034)$, as are the larger differences between Web of Science and the other databases with lower coverage. Eight of the 11 journals not indexed by Web of Science were veterinary titles, and only two were still being published. However, CAB Abstracts covered all of these veterinary titles.

The number and percentage of journal titles from monographs and Plumb's zone 1 and 2 as well as JVPT zone 1 held by libraries serving colleges of pharmacy or veterinary medicine are shown in Table 4 . Six of the journals (22\%) provided open access to content after an embargo of 12 months or less and were considered to have coverage regardless of whether they appeared in a library's catalog or journal lists. Libraries serving a combination of pharmacy and veterinary medicine schools $(n=14)$ average $95 \%$ coverage of the core journals; for the 13 libraries serving co-located programs, the average is $98 \%$. Libraries serving a veterinary medicine program but not a pharmacy program had $97 \%$ of the journals. Holdings are significantly lower $(59 \%)$ for libraries serving schools of pharmacy at institutions without a veterinary program than those with both programs $(\mathrm{z}=2.6, p=.008)$. The difference in mean titles held by libraries without a veterinary program serving pharmacy schools who offered a veterinary elective in 2015 (18.4) versus those that did not (15.6) was not significant $(t=1.527, \mathrm{df}=116, p<.13)$.

\section{DISCUSSION}

As expected, for the evolving profession of veterinary pharmacy, which relies heavily upon clinical application of new medical research, journals were the most 


\section{American Journal of Pharmaceutical Education 2020; 84 (10) Article 7314.}

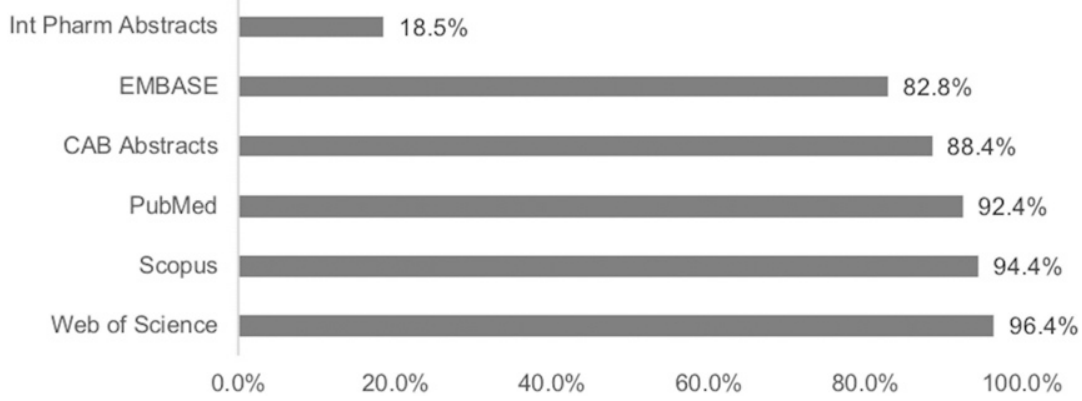

Figure 1. Indexing Coverage by Database for Zone 1 Journals From All Sources and Zone 2 Journals from AAVPT and Plumb's $(\mathrm{N}=303)$

Abbreviations: AAVPT = American Academy of Veterinary Pharmacology and Therapeutics, JVPT=Journal of Veterinary

Pharmacology and Therapeutics, Int Pharm Abstracts=International Pharmaceutical Abstracts

commonly cited reference type (79.4\%) across all mapped citations. The large number of conference proceedings cited in Plumb's but not in the other two sources was an interesting finding. Proceedings tend to be the most contemporary source of clinical information, and can be mined on a consistent basis to determine current thinking for clinical veterinary pharmacotherapy. Plumb's cited 747 conference proceedings that were less than 10 years old, while JVPT cited 36 and the monographs cited only five. Comprehensively using primary literature for every dose of every drug used for every indication in animals requires a skilled knowledge filter to critically evaluate and apply the cited literature. Because most pharmacists lack the training to develop such knowledge-based filters for veterinary patients, the use of conference proceedings to determine "consensus" dosing in veterinary medicine is a valuable tool for pharmacists who are caring for animal patients. Conference proceedings, which may or may not be peer-reviewed, contribute novel information related to the field of veterinary pharmacy and makes them worthy of consideration for health sciences library holdings. Options to increase the discoverability of veterinary pharmacy literature include encouraging the use of biomedical databases to index other veterinary titles in addition to those listed here, as well as conference proceedings from major veterinary symposia.

Health sciences libraries serving veterinary medicine and pharmacy had access to literature from both fields needed to support practice and research in veterinary pharmacy. Newer schools may need to develop digital collections or form partnerships with other health sciences libraries to ensure students have convenient access to relevant materials. Access to veterinary pharmacy literature at libraries supporting pharmacy schools without a veterinary program varies tremendously. Subscriptions to even the core journals relevant to veterinary pharmacy appear infrequent with only $27 \%$ of those

Table 3. Top 10 Journals Cited in Veterinary Pharmacy and Pharmacology Literature as Represented by AAVPT Monographs, JVPT, and Plumb's

\begin{tabular}{|c|c|c|c|}
\hline Rank & AAVPT Monographs & JVPT & Plumb's \\
\hline 1 & Am J Vet $\operatorname{Res}^{\mathrm{a}}$ & J Vet Pharmacol Ther ${ }^{\mathrm{a}}$ & 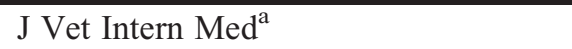 \\
\hline 2 & J Vet Pharmacol Ther ${ }^{\mathrm{a}}$ & Am J Vet Res ${ }^{\mathrm{a}}$ & J Vet Pharmacol Ther ${ }^{\mathrm{a}}$ \\
\hline 3 & $\mathrm{~J}$ Am Vet Med Assoc ${ }^{\mathrm{a}}$ & Antimicrob Agents Chemother ${ }^{\mathrm{b}}$ & Vet Clin North Am: Exotic Anim Pract \\
\hline 4 & Vet Rec & $\mathrm{J}$ Vet Intern $\mathrm{Med}^{\mathrm{a}}$ & Vet Clin North Am: Small Anim Pract \\
\hline 5 & Res Vet $\mathrm{Sci}^{\mathrm{b}}$ & Vet $\mathrm{J}$ & Am J Vet Res ${ }^{\mathrm{a}}$ \\
\hline 6 & Antimicrob Agents Chemother ${ }^{\mathrm{b}}$ & Equine Vet $\mathrm{J}^{\mathrm{b}}$ & $\mathrm{J}$ Am Vet Med Assoc ${ }^{\mathrm{a}}$ \\
\hline 7 & Equine Vet $\mathrm{J}^{\mathrm{b}}$ & Res Vet $\mathrm{Sci}^{\mathrm{b}}$ & Vet Anaesth Analg ${ }^{\mathrm{b}}$ \\
\hline 8 & Can Vet $\mathrm{J}$ & $\mathrm{J}$ Am Vet Med Assoc ${ }^{\mathrm{a}}$ & J Vet Emerg Crit Care \\
\hline 9 & J Am Anim Hosp Assoc & Vet Anaesth Analg ${ }^{\mathrm{b}}$ & Vet Clin North Am: Food Anim Pract \\
\hline 10 & $\mathrm{~J}$ Vet Intern $\mathrm{Med}^{\mathrm{a}}$ & Drug Metab Dispos & Vet Dermatol \\
\hline
\end{tabular}

Abbreviations: AAVPT =American Academy of Veterinary Pharmacology and Therapeutics, JVPT= Journal of Veterinary Pharmacology and Therapeutics

a Titles are in the top 10 from all three sources

${ }^{\mathrm{b}}$ Titles are in the top 10 on two of the three lists. See Appendix 1 for full journal titles 


\section{American Journal of Pharmaceutical Education 2020; 84 (10) Article 7314.}

Table 4. Access to Veterinary Pharmacy and Pharmacology Journals (N=27) Identified as Zone 1 and 2 in AAVPT Monographs and Plumb's and Zone 1 for JVPT Through Libraries ${ }^{a}(\mathrm{~N}=148)$ Serving Colleges of Pharmacy or Veterinary Medicine

\begin{tabular}{lcc}
\hline Type and Number of Libraries & $\begin{array}{c}\text { Number of Titles Held } \\
\text { M (SD) }\end{array}$ & $\begin{array}{c}\text { Percentage of Titles Held } \\
\text { (Range of Percentages) }\end{array}$ \\
\hline Both pharmacy and veterinary medicine programs ( $\mathrm{n}=14$ libraries) & $25.7(2.9)$ & $95(59-100)$ \\
Veterinary medicine, no pharmacy program ( $=16$ libraries) & $26.2(1.2)$ & $97(85-100)$ \\
Pharmacy, no veterinary medicine program $(\mathrm{n}=118$ libraries) & $15.9(6.3)$ & $59(22-100)$ \\
Pharmacy reporting veterinary elective ( $=13$ libraries) & $18.4(4.6)$ & $68(37-96)$ \\
Pharmacy not reporting veterinary elective ( $=105$ libraries) & $15.6(6.4)$ & $58(22-100)$ \\
\hline
\end{tabular}

AAVPT $=$ American Academy of Veterinary Pharmacology and Therapeutics, JVPT=Journal of Veterinary Pharmacology and Therapeutics

${ }^{a}$ Libraries serving multiple campuses of colleges of pharmacy that appear to share access to resources are counted once. Libraries for whom journal holdings were not publicly discoverable $(n=10)$ were excluded

libraries subscribing to the three journals identified in Table 3 as being in the top 10 across all lists: $42 \%$ have the American Journal of Veterinary Research, $47 \%$ have the Journal of the American Veterinary Medical Association, and $61 \%$ have $J V P T$. The Journal of Veterinary Internal Medicine is open access and therefore accessible by all schools. Although not assessed, we assumed libraries supporting pharmacy programs at institutions without a veterinary medicine program do not hold veterinary conference proceedings. Journal subscriptions may have changed since we searched most of the holdings in 2018. Our focus on journal literature from 2016-2018 may also not have captured any newer journals that would be relevant. The development of veterinary pharmacy education programs in schools of pharmacy ${ }^{20}$ should encourage institutional libraries to develop access to relevant collections. Libraries serving pharmacy education might partner with libraries serving veterinary medicine, animal science, and agriculture, which are likely to have access to databases like CAB Abstracts (aka VetMed Resource).

Veterinary pharmacy information largely draws on human medicine journals, veterinary journals, pharmacy books, and veterinary conference proceedings. Literature on antimicrobial agents represents crucial overlap between human and veterinary pharmacy as both our study and the human hospital core pharmacy study ${ }^{8}$ found $\mathrm{An}$ timicrobial Agents \& Chemotherapy to be a core journal. While antimicrobials and other medications common to humans and their pets may seem straightforward, a pharmacist predominantly dispensing for companion animals may be called upon to evaluate drug research in an exotic or large animal species to provide appropriate drug information and therapeutic recommendations. Therefore, having access to literature resources for all animal species, as well as a basic comprehension of veterinary medical literature, would be beneficial for all pharmacy students. Conducting comprehensive and effective web searches remains an essential skill for pharmacists to have and for pharmacy students to develop as veterinary drug manufacturer information is a significant information source. Knowledge and availability of pertinent literature is critical to both veterinarians and pharmacists so that they may collaborate effectively on providing quality pharmacy care to their patients of all species.

\section{CONCLUSION}

Veterinary pharmacists are at the forefront of comparative medicine as the only health care professionals legally permitted to provide pharmaceutical care to all species. Treating veterinary patients often requires data extrapolation from human medicine; therefore, having access to relevant human and veterinary medicine resources is paramount. The data here can serve as a guide to pharmacists by delineating where pertinent veterinary medical information is located, what sources are most frequently used to support articles and monographs, and what types of cited references may be unique to veterinary monographs. Whether a novice or expert in veterinary pharmacy, being familiar with and having access to the most commonly cited references in veterinary monographs will inform a pharmacist's drug information research and, ultimately, patient care.

\section{ACKNOWLEDGMENTS}

Stephanie Folkerts, Alix Vo, and other public service assistants at the William Rand Kenan, Jr. Library of Veterinary Medicine extracted citation data and gathered indexing information and library journal holdings. Donald C. Plumb shared a digital copy of the references used in the Plumb's Veterinary Drug Handbook for our analysis.

\section{REFERENCES}

1. Arnish CE, Davidson GS, Royal K. Veterinary pharmacy education: prevalence and perceptions. Poster presented at: Society of Veterinary Hospital Pharmacists, 34th Annual Meeting; June 14-17, 2015; Portland, ME. 


\section{American Journal of Pharmaceutical Education 2020; 84 (10) Article 7314.}

2. Sorah E, Davidson G. Royal K. Dispensing errors for non-human patients in the community pharmacy setting: A survey of pharmacists and veterinarians. Poster presented at: Society of Veterinary Hospital Pharmacists, 34th Annual Meeting, June 14-17, 2015; Portland, ME. 3. Mingura M. Community pharmacists and veterinary prescriptions: An analysis of prevalence, type, training, and knowledge retention. Poster presented at: Society of Veterinary Hospital Pharmacists 36th Annual Meeting, June 12-14, 2017; Portland, OR.

4. Guidance for Industry; Availability; Withdrawal of Compliance Policy Guide; Section 608.400 Compounding of Drugs for Use in Animals. Federal Register website. https:/www.federalregister.gov/ documents/2015/05/19/2015-11982/compounding-animal-drugsfrom-bulk-drug-substances-draft-guidance-for-industry-availability. Accessed September 18, 2020.

5. National Association of Boards of Pharmacy resolution 110-5-14. Veterinary Pharmacy Education (5 May 2014). https:// nabp.pharmacy/newsroom/news/veterinary-pharmacy-educationresolution-110-5-14/. Accessed September 18, 2020.

6. Ugaz AG. Drilling deeper into the core: an analysis of journal evaluation methodologies used to create the "Basic List of Veterinary Medical Serials," third edition. J Med Libr Assoc.

2011;99(2):145-152.

7. Schloman BF. Mapping the literature of allied health: project overview. Bull Med Libr Assoc. 1997;85(3):271-277.

8. Barrett A, Helwig M, Neves K. Mapping the literature of hospital pharmacy. J Med Libr Assoc. 2016;104(2):118-124.

9. Vreeland CE, Alpi KM, Pike CA, Whitman EE, KennedyStoskopf S. Access to human, animal, and environmental journals is still limited for the One Health community. J Med Libr Assoc. 2016;104:100-108.
10. Bradford S. Documentation. London, UK: Crosby, Lockwood, 1948.

11. National Library of Medicine. List of journals indexed in PubMed. ftp://ftp.ncbi.nih.gov/pubmed/J_Medline.txt. Accessed September 18, 2020.

12. Elsevier. Embase Journal List. https://www.elsevier.com/ solutions/embase-biomedical-research/embase-coverage-and-content. Accessed September 18, 2020.

13. International Pharmaceutical Abstracts (IPA) Source List September 29, 2019. Clarivate Analytics. Obtained from publisher by request.

14. CABI. CAB Abstracts Serials Cited. https://www.cabi.org/ publishing-products/cab-abstracts/. Accessed September 18, 2020. 15. Analytics Clarivate. Web of Science Master Journal List. https://mjl.clarivate.com/home. Accessed September 18, 2020. 16. Scopus. Source List. https://www.scopus.com/sources.uri? DGCID = Scopus_blog_post_check2015. Accessed September 18, 2020.

17. Sergeant ESG. Epitools epidemiological calculators. Ausvet Pty Ltd., 2018. http://epitools.ausvet.com.au. Accessed September $18,2020$.

18. Association of American Veterinary Medical Colleges website. https://www.aavmc.org/aavmc-members/full-member-listing. Accessed September 18, 2020.

19. American Association of Colleges of Pharmacy Institutional Membership website. https://www.aacp.org/article/aacpinstitutional-membership\#InstMembers. Accessed September 18, 2020.

20. Theberge CR, Sehgal I. Bringing more veterinary pharmacy into the pharmacy curriculum. Am J Pharm Educ 2016;80(5):89. 
American Journal of Pharmaceutical Education 2020; 84 (10) Article 7314.

Appendix 1. List by Abbreviation of Journals Included in Zone 1 from Journal of Veterinary Pharmacology and Therapeutics or Zone 1 or 2 from American Academy of Veterinary Pharmacology and Therapeutics Monographs or Plumb's Veterinary Drug Handbook, $\mathrm{N}=27$

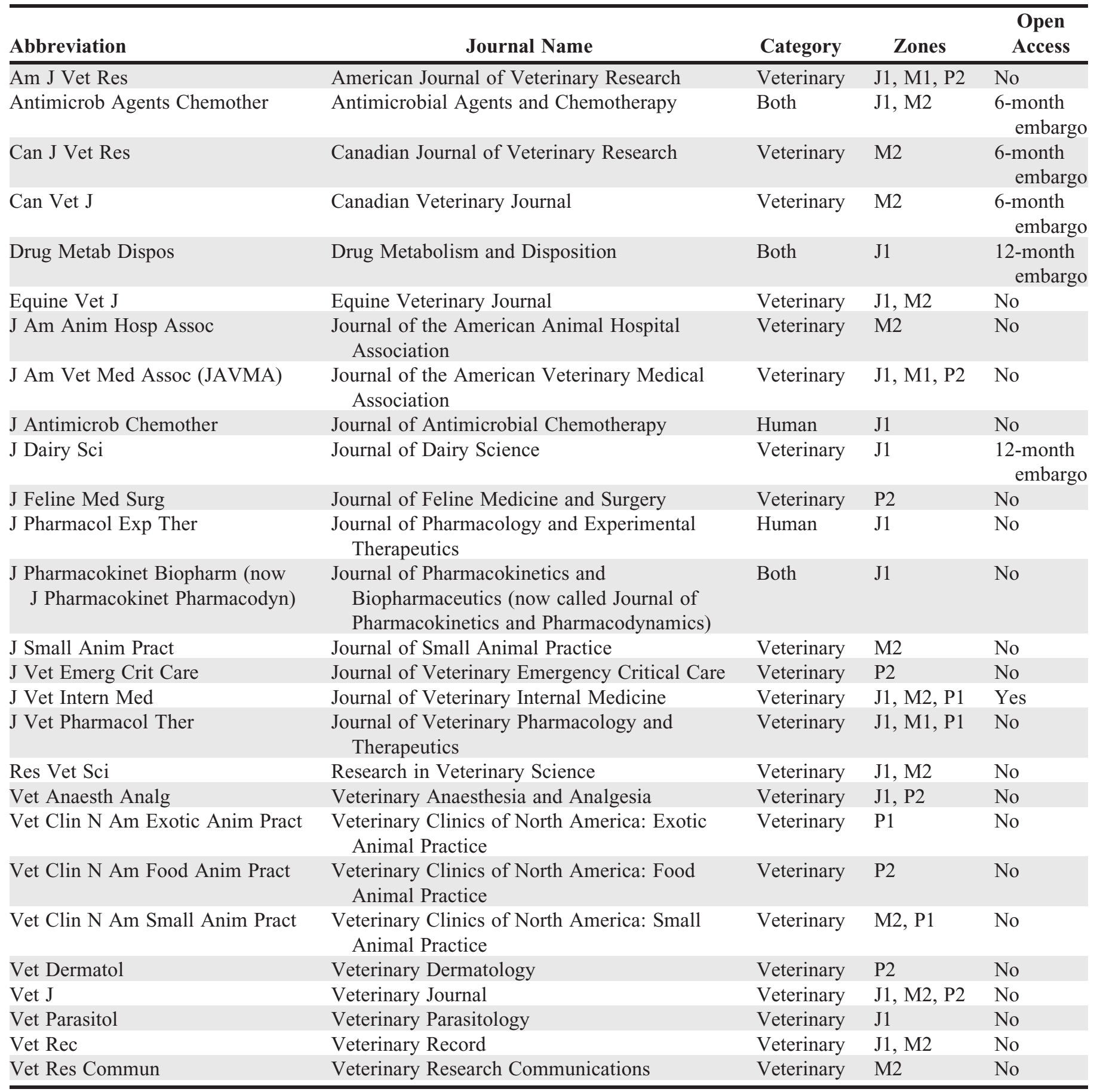

$\mathrm{J} 1=J V P T$ Zone 1, M1 = Monographs Zone 1, M2=Monographs Zone 2, P1=Plumb's Zone 1, P2=Plumb's Zone 2 